\title{
UMA EDUCAÇÃO PARA A AUTODETERMINAÇÃO A PARTIR DA TEORIA DO AGIR COMUNICATIVO DE HABERMAS
}

\section{AN EDUCATION FOR SELF-DETERMINATION FROM HABERMAS'S THEORY OF COMMUNICATIVE}

\author{
Francisco Antonio de Vasconcelos* \\ franciscoantonio_vasconcelos@yahoo.com.br
}

\section{RESUMO}

Este artigo tem como objetivo debater a respeito da importância da teoria do agir comunicativo do filósofo e sociólogo alemão para a realização de um agir pedagógico que contribua para a emancipação do indivíduo e da sociedade. Nele, será lembrado que Habermas não possui uma teoria da educação, também serão apresentadas as contribuições de sua teoria do agir comunicativo para uma educação emancipadora e se aprofundará a discussão sobre as possibilidades do pensamento de Habermas para a elaboração de um agir educacional que leve à autodeterminação da pessoa.

Palavras-chave: educação, agir comunicativo, autodeterminação.

\begin{abstract}
This paper aims to discuss about the importance of the theory of communicative action of the philosopher and sociologist Jürgen Habermas to conduct a pedagogical act that contributing to the empowerment of the individual and society. In it will be remembered that Habermas does not have a theory of education, will also be featured contributions from his theory of communicative action for an emancipatory education and deepen the discussion about the possibilities of thought Habermas for the elaboration of an educational act that leads to self-determination of the person.
\end{abstract}

Keywords: education, communicative action, self-determination.

\section{INTRODUÇÃO}

Neste artigo, pretende-se apresentar a teoria do agir comunicativo do professor Jürgen Habermas como um importante instrumento capaz de oferecer contribuições significativas na busca de respostas eficientes aos problemas educacionais, no contexto do século XXI.

\footnotetext{
* Graduação e Mestrado em Filosofia; Especialização em Língua e Literatura Latina; Doutorado em Ciências da Educação; Professor Adjunto da Universidade Estadual do Piauí (Desde 2009). Dentre outras obras, é autor de Habermas e o conteúdo normativo da modernidade. Desenvolve as Linhas de Pesquisa Habermas e a Educação, Religião e Política e, Clero e Sociedade.
} 
Contudo, é correto dizer que Habermas não se interessou diretamente pelos aspectos pedagógicos ou institucionais do ensino a ponto de apresentar uma teoria da educação. Aqui, porém, levou-se em conta que o pensamento de Habermas em seu conjunto e, de modo especial, sua teoria do agir comunicativo tem muito a oferecer à educação. Podemos destacar alguns conceitos como educação, autodeterminação, pessoa, razão comunicativa modernidade, Princípio do Discurso, Princípio de Universalização, democracia, liberdade, por exemplo.

As contribuições da teoria do agir comunicativo de Habermas para uma educação que pretenda a autodeterminação da pessoa, fazendo avançar o projeto de sua emancipação, dentre outras coisas, deve buscar realizar a democratização do conhecimento. Democratizar o conhecimento aparece como elemento imprescindível para que se avance na construção da liberdade do indivíduo. Assim, as reflexões aqui apresentadas estão diretamente ligadas à tradição kantiana da "Aufklärung". No que diz respeito ao núcleo dos ideais da Aufklärung, Habermas se liga a Kant, dado que sua teoria crítica quer contribuir com o esclarecimento dos homens.

O último tópico deste artigo trata especificamente da relação entre a autodeterminação e a educação em Habermas. Para isto, parte de uma questão levantada pelo filósofo Düsseldorf, no Kleine politische Schriften (I-IV), isto é, definir o projeto da modernidade e saber se ele ainda continua valendo ou não. Habermas defende que esse projeto ainda está por ser concretizado. Significa dizer que se trata de um projeto que assume o status de inacabado (unvollendetes).

Considerando os pontos principais da teoria do agir comunicativo, tal como a entende Habermas, queremos mostrar que ela está habilitada a contribuir para a autodeterminação da pessoa humana. Mas, será preciso afastar-se da filosofia da consciência, focada no sujeito, e utilizar o paradigma linguístico, centrado na intersubjetividade e que serve de base para a idéia de racionalidade comunicativa.

Não obstante, vale lembrar que a noção de racionalidade comunicativa além de ser de natureza sociológica é também de natureza filosófica. A idéia de razão comunicativa está, em Habermas, no

$:: 32::$ centro de uma filosofia que quer ser universalística, anticética e pós-metafísica.

\section{HABERMAS NÃO TEM UMA TEORIA DA EDUCAÇÃO}

De fato, pode-se afirmar que Jürgen Habermas não se interessou diretamente pelos aspectos pedagógicos ou institucionais do ensino. Isto explica porque não encontrarmos nele uma teoria da educação. Encontramos nele, por exemplo, uma teoria da razão, uma teoria da modernidade, uma teoria moral (sua ética do discurso) e uma teoria da sociedade. Aliás, é preciso ressaltar que, em sua Teoria do agir comunicativo, o grande objetivo é elaborar uma teoria da sociedade. Tal objetivo estará presente direta ou indiretamente em seus trabalhos posteriores. Neles podemos encontrar os elementos necessários a quem desejar construir uma teoria da educação a partir do pensamento desse filósofo/sociólogo.

Nesse sentido, é importa destacar alguns conceitos. Vejamos:

\section{- Educação:}

O conceito de educação utilizado nesta pesquisa é herdeiro de uma linhagem de pedagogos (Carl Rogers, Howard Gardner, Edgar Morin, Henri Wallon, Celestin Freinet, B. F. Skinner, Jean Piaget, Paulo Freire dentre outros) que entendem ser a educação um instrumento cuja finalidade é a emancipação do "indivíduo" de todas as amarras que o impedem de tornar-se um ser livre na dimensão possível à natureza humana. O solo desta concepção é a idéia de que este indivíduo, de fato, não existe só nem fora do tempo ou do espaço.

Ao contrário, de um lado, ele é um ser que existe com e a partir de outros indivíduos tendo em relação a estes direitos e/ou deveres; por outro lado, sua existência é situada no tempo e no espaço, isto é, ele é um ser histórico e tem um habitat, o planeta terra. Portanto, ele tem responsabilidades com a história, quer dizer, deve dar sua contribuição a fim de que o legado deixado pelas gerações que existiram antes dele seja preservado, por um lado; por outro, ele deve se esforçar para 
entregá-lo às gerações futuras não do mesmo jeito que o recebeu, mas melhorado. Tem também responsabilidades em relação ao planeta em que habita. Não lhe é permitido existir nesse planeta de forma parasitária.

Isto significa dizer que é próprio dessa concepção de "educação", compreender o ser humano como alguém que pode e deve atuar no espaço público como participante ativo e não como mero observador. É vidente que neste processo ele precisa ser auxiliado. Algumas vezes mais outras vezes menos, mas jamais deverá deixar de ser sujeito desse processo.

\section{- Autodeterminação:}

Este conceito deve ser entendido a partir de outro, a saber: o de "esclarecimento" (Aufklärung). Assim, deve-se responder a duas questões: Primeiro, qual é a situação do esclarecimento na era atual? Segundo, como situar Jürgen Habermas no tema "esclarecimento"?

Vamos à primeira questão. Horkheimer, em seu livro de 1967 intitulado Zur Kritik der strumentellen Vernunft (Para a crítica da Razão instrumental), diz que somos herdeiros do pensamento esclarecedor, quer queiramos ou não (1967: 123). É fato que, na atualidade, o pensamento esclarecedor é contestado através das mais variadas formas. A razão, que constitui a mola mestra do esclarecimento, também é objeto de veementes contestações.

Contudo, segundo lembra o professor Siebeneichler em seu livro Jürgen Habermas: Razão comunicativa e emancipação, nossa sociedade não pode mais abrir mão dos conceitos iluministas: razão, ação, sujeito, pessoa, emancipação, humanidade libertada, linguagem, dentre outros (1994: 11-12). Prossegue ele: é necessário esclarecer o esclarecimento. É verdade que o esclarecimento traz, já em suas origens, uma fé ingênua nas ciências e nos costumes. Este fato será alvo das críticas de Kant, Hegel e Marx. Eles, contribuidores importantíssimos para o processo inacabado de emancipação do ser humano. Em nosso século, entretanto, retoma-se a filosofia prática. Isto resultará na revalorização do esclarecimento.

Passemos à segunda. Nosso pensador de Düsseldorf, que é um teórico crítico ${ }^{1}$, diz que o esclarecimento dos filósofos dos séculos XVIII e XIX é um projeto da modernidade. Para ele, tal projeto possui duas tarefas: a primeira delas é desenvolver três esferas de potencial racional e cognitivo (a das ciências objetivantes, a das bases universalistas do direito e da moral e, por último, a esfera da arte autônoma); a outra é utilizar este potencial cognitivo para o bem da formação racional do homem numa sociedade emancipada (1994: 21).

De acordo com o professor Habermas, a questão que se apresenta é a seguinte: O projeto do esclarecimento ainda está de pé? Ou devemos abandoná-lo? Para ele, devemos continuar com tal projeto. Nosso filósofo/sociólogo defende a emancipação da humanidade pelo esclarecimento e pela formação racional do indivíduo humano e das coletividades.

O esclarecimento habermasiano está apoiado numa razão situado historicamente na práxis social, estamos falando da razão comunicativa. Então, o esclarecimento é visto como um processo de argumentação entre a razão e a esfera da dominação (1994: 22). Este esclarecimento quer também levar o homem a utilizar a razão comunicativa. Neste sentido, conforme o professor Siebeneichler, para Habermas, o que caracteriza a emancipação do homem é a convivência em um contexto de uma comunicação não coagida.

\section{- Pessoa:}

A pessoa para Habermas apresenta dois atributos importantes, a saber: ela é capaz de falar e de agir. É, portanto, um ser de relações. Afirma-se, pois, que é intrínseca à pessoa a capacidade de linguagem (homo loquens); que sua existência depende da existência das outras pessoas; ela é por isso um ser social, gregário, comunitário; suas tomadas de decisões são influenciadas e influenciam a das outras pessoas; quer dizer também que toda pessoa, e cada uma em particular, é portadora de direitos e de deveres; que sua relação com as demais deve ser respeitosa, solidária, 
justa, fraterna; que ela é dotada de inteligência, sendo assim capaz de aprender com as gerações anteriores e de gerar conhecimento para as gerações futuras, o que a faz um ser cultural; dizer que a pessoa é dotada de capacidade de fala e de ação serve para orientar também o comportamento do homem com a natureza, pois, caso esse relacionamento não seja sadio, a existência mesma da humanidade é posta em xeque.

Enfim, significa dizer que ela é um ser racional. Contudo, Habermas rejeita a razão positivista que traz em si as marcas de uma razão opressora, pois, na prática, tende a conceber a pessoa como sendo absolutamente racional. Habermas então substitui essa idéia de razão por outra que, ao invés de oprimir, emancipa o ser humano.

Contudo, defender que somos capazes de falar e de agir quer dizer ainda que somos seres situados no tempo e no espaço, isto é, somos seres históricos. Portanto, o nosso futuro não está previamente estabelecido. Ao contrário, vai sendo tecido paulatinamente através de cada tomada de decisão pelo "sim" ou pelo "não", como diz Habermas. Se a pessoa decide mal, ou seja, faz mau uso de sua capacidade de falar e de agir, ela vai perdendo sua autonomia, vai se deixando escravizar, vai abrindo mão de sua capacidade de se autodeterminar; de outro modo, caso ela saiba exercer bem sua racionalidade comunicativa, através de cada tomada de decisão, isto é, de cada fala proferida e de cada ação executada vai surgindo uma pessoa livre, emancipada.

\section{- Razão comunicativa:}

Habermas, em seu trajeto intelectual, irá realizar uma mudança de paradigma. Ele deixará de lado a idéia de uma razão que procedia essencialmente por meio da auto-reflexão e irá trabalhar com a noção de que a razão é essencialmente comunicativa. A razão, para ele, reside no ato de fala, característica de toda pessoa humana. Essa razão comunicativa deseja a realização do consenso entre as pessoas envolvidas em uma discussão, em um debate, no qual todos os envolvidos são convidados a levantar e defender suas pretensões de validade. Esta razão tem a tarefa de emancipar a humanidade. O conceito de razão comunicativa é fundamental para a elaboração da teoria da modernidade habermasiana.

$:: 34::$

- Modernidade:

Para Habermas, a modernidade é um projeto inacabado, conforme falamos anteriormente. Isto significa dizer que ela possui um potencial ainda por atualizar-se. Assim, pois, é certo afirmar que não se pode menosprezar o ideal emancipatório proposto por ela. Sobre isto, temos Modernität: Eine unvollendetes Projekt (Modernidade: Um projeto inacabado) publicado em 1980. Fundamental para compreender o que Habermas pensa sobre a modernidade é sua obra de 1983, intitulada $O$ discurso filosófico da modernidade. Contudo, sua teoria da modernidade aparece elaborada em Teoria do agir comunicativo, já mencionada atrás.

Ele lembra que na atualidade as três linhas mais importantes ocupadas com a tarefa de compreender o que se passa nas sociedades modernas são a história das sociedades (que tem por base o pensamento de Max Weber), a teoria do sistema (desenvolvida por Parsons e Luhman) e a teoria da ação (elaborada pelo interacionalismo simbólico, pela hermenêutica e pela fenomenologia). Por sua vez, Habermas elabora o seu "estruturalismo genético" cuja tarefa é explicar as patologias que ameaçam a modernidade as quais foram olvidadas pelas outras linhas mencionadas acima. Ele, lançando mão dos conceitos de "mundo da vida" e "sistema", vai propor que a origem dessas patologias reside no seguinte: toda vez que as formas de integração social são suprimidas pelo sistema aumentará o nível de colonização do mundo da vida. O resultado desta colonização será um crescimento das patologias nas sociedades modernas.

Com o conceito de "colonização do mundo da vida", ele queria encontrar algo que substituísse a teoria do valor elaborada por Karl Marx. Habermas quer que a teoria da reificação seja reproposta em termos de uma cisão entre sistema e mundo da vida. A modernidade será analisada por nosso autor do seguinte modo: de um lado, ele descreve o desenvolvimento de aumento em complexidade sistêmica; de outro, analisa a diferenciação das esferas de valores culturais. Quanto ao sistema, observa-se que as formas da sociedade se organizar sofrerá influência de um novo princípio (dinheiro e poder, respectivamente corporificados nos sistemas econômicos e administrativos). No que tange à cultura, para Habermas, a modernidade experimenta uma nova estruturação racional, 
a saber: pós-convencional. Ela aparece sob a forma de três esferas autônomas entre si, são elas: ciência (verdade), moralidade (correção normativa) e arte (autenticidade).

Para ele, a modernidade significa um avanço indiscutível, quer se trate da razão instrumental quer se trate da razão comunicativa. Ele defende que um mérito imensamente significativo da modernidade foi ela ter liberado o potencial da razão comunicativa. Para Habermas, o que deve ser combatido é a constante intromissão da razão instrumental no território da razão comunicativa, uma vez que esta interferência produz as patologias sociais, ou seja, os efeitos negativos percebidos ao nível da cultura, da sociedade e da personalidade.

O que ele propõe é que se lute a fim de que as duas razões sejam reconciliadas. Esta reconciliação significa o seguinte: a modernidade ameaçada voltaria a desenvolver o potencial de racionalidade ainda não esgotado por ela. Assim, o potencial emancipatório que veio à tona com a modernidade poderia se tornar realidade.

- Princípio do Discurso:

O conceito de "Princípio do Discurso" aqui apresentado é tirado de um artigo de Habermas intitulado Moralität und Sittlichkeit. Treffen Hegels Einwände gegen Kant auch auf Diskursethik zu? (Moralidade e eticidade: As objeções de Hegel contra Kant valem também em relação à ética do discurso?) que foi publicado em 1986, num livro organizado por Kuhlmann. Ele é o princípio da ética do discurso. Este princípio reza: Podem pretender validade apenas as normas que encontram (ou podem encontrar) o consenso de todos os sujeitos envolvidos enquanto participantes de um discurso prático (1986: 19). Ele conduz, portanto, ao discurso prático, à argumentação moral. Na verdade, o princípio da ética do discurso atribui a fundamentação das normas ao discurso prático. O problema da validade dos juízos morais aponta para a questão da lógica do discurso prático.

Ele será importante para uma educação emancipadora, sobretudo, porque diz o seguinte: norma válida é aquela que foi submetida ao consenso de todos os envolvidos e foi aprovada. Assim, ele aponta para a inclusão social de todos. Oferece pressuposto teórico para a construção de um discurso condenatório de todo e qualquer tipo de exclusão social. Além de abrir caminho para uma prática que conduza à emancipação da pessoa humana, tirando-a da condição vil de não-ator no espaço público, em que os rumos da sociedade são traçados; colocando-a no centro dessas discussões a fim de que exerça seu papel de cidadão, sempre e cada vez melhor.

- Princípio de Universalização:

Este conceito nós iremos encontrar na mesma obra referida acima. Ele é a regra de argumentação nos discursos práticos. Eis como Habermas o formula: "Nas normas válidas, devem poder ser aceitas por parte de todos, sem constrições, os resultados e as conseqüências secundárias que derivam de sua universal observância para a satisfação dos interesses de cada um" (1986: 19).

A importância desse princípio para pensar uma educação emancipadora reside, de modo especial, nisto: Ela diz que as normas, uma vez submetidas à aprovação dos participantes do discurso (e todos os interessados devem poder participar), suas conseqüências devem ser aceitas por todos, ou seja, este princípio aponta para uma atitude responsável por parte do sujeito social. Se o princípio do discurso aponta para os direitos da pessoa humana, este nos lembra de seus deveres.

\section{- Democracia:}

Pontos importantes das idéias de Habermas sobre a democracia, que aparecem em sua obra Teoria do agir comunicativo (vols. I e I), são retomados em Faktizität und Geltung, traduzida para Direito e democracia: Entre faticidade e validade, em 1994.

A professora Santos (trabalhando a relação entre democracia e educação partindo do pensamento de Habermas, em seu livro Cidadania no discurso da modernidade: Uma interpelação à razão comunicativa lançado em 2003) lembra que "[...] educar para a cidadania não pode se restringir à conscientização dos direitos e deveres, ... mas requer o reconhecimento da necessária competência político/social ...que possibilite a participação no espaço público das negociações" (2003: contracapa).

A noção de democracia utilizada na tese de doutorado é apoiada no conceito de cidadão apresentado acima, quer dizer: de um lado, para que um indivíduo possa ser dito cidadão, faz-se necessário que ele possua direitos e deveres; por outro, é preciso que ele participe da elaboração desses direitos e 
deveres (Princípio D e Princípio U, respectivamente). Portanto, estamos totalmente de acordo com o que diz a professora Santos.

- Liberdade:

No que diz respeito à liberdade, o pensamento de Jürgen Habermas é devedor das idéias de Immanuel Kant, o maior representante do projeto filosófico da modernidade, projeto cuja principal bandeira era a emancipação da pessoa. Claro, as teses deste último estão ligadas a um contexto metafísico, ao passo que as daquele situam-se em um terreno pós-metafísico. ${ }^{2}$

É no modo de compreender a razão que o pensamento de Habermas e Kant sobre a liberdade deve ser abordado. A "razão prática" de Kant, em Habermas se transforma em "razão comunicativa". Temos a partir dessas concepções de razão duas formas de considerar a liberdade que, a um só tempo, se distanciam e se aproximam. A principal diferença, entretanto, é a seguinte: no filósofo de Könisberg ela aparece como capacidade de autocontrole puramente subjetiva, ao passo que no filósofo/sociólogo de Dürseldorf a liberdade surge como resultante de procedimentos estabelecidos intersubjetivamente.

\section{Contribuições da Teoria do Agir Comunicativo de Habermas para uma educação emancipadora}

\subsection{A democratização do conhecimento}

\section{Introdução}

O trabalho apresentado tem como pano de fundo a liberdade humana. Democratizar o conhecimento surge, então, como elemento imprescindível para que se avance na construção dessa liberdade. Desse modo, as reflexões aqui apresentadas estão diretamente ligadas à tradição kantiana da ::36:: "Aufklärung".

A noção de que todos devem ter direito ao conhecimento é desenvolvida aqui a partir de dois conceitos, são eles: o "contexto de constituição" e o "contexto de aplicação" do conhecimento. Aquele defende que todos devem poder participar do processo de produção do conhecimento, e este lembra que as conquistas da Filosofia, das Ciências, da técnica, etc devem estar à disposição de todos.

A segunda parte, cujo título é "O que fazer?", procura apresentar um caminho através do qual se possa chegar de fato a um saber democrático tanto em sua constituição quanto em sua aplicação. O caminho proposto é a teoria crítica elaborada por Jürgen Habermas, mais especificamente sua teoria do agir comunicativo. Suas ligações com a "Aufklärung" kantiana são aqui destacadas.

\subsubsection{O que se quer?}

Kant em seu famoso trabalho intitulado Resposta à pergunta o que é ilustração diz: "A ilustração consiste no fato pelo qual o homem sai da menoridade. Ele mesmo é culpado dela. A menoridade está estribada na incapacidade de servir-se do próprio entendimento, sem a direção de alguém. A pessoa mesma é culpada desta menoridade, quando a causa dela não jaz em um defeito do entendimento, mas na falta de decisão e ânimo para servir-se com independência dele, sem a condução de outra pessoa. Sapere aude! Ousa servir-te de teu próprio entendimento! Eis aqui a divisa da llustração" (2004: 33).

Essa expressão latina usada por Kant serve para reforçar a idéia, presente neste artigo, de que o homem é, por essência, livre. Não entendemos aqui uma liberdade descontextualizada da situação histórica em que a pessoa vive, dado que cada indivíduo deve ser um cidadão (que além de direitos possui deveres) e é nesse cidadão que a liberdade ira se materializar. Contudo, entendemos que

2..Confira-se HABERMAS, Jürgen. (1990) Pensamento pós-metafísico: Estudos filosóficos. Rio de Janeiro: Tempo Brasileiro. 
no exercício de sua cidadania todo indivíduo deve gozar de liberdade plena, de forma que cada um possa participar da elaboração de seus direitos e deveres (Vasconcelos, 2006: 72-83).

Para alcançar essa meta, será conditio sine qua non a democratização do saber. Deve-se destacar aqui que a democratização do saber tem duas pontas: de um lado o contexto de constituição do conhecimento, ou seja, toda pessoa deve poder ter acesso ao processo de produção do conhecimento; de outro lado temos o contexto de aplicação do conhecimento adquirido pela humanidade, isto é, os resultados da produção desse conhecimento.

No que tange a democratização do saber, infelizmente, nossa experiência atual mostra que há muito a ser feito para que as conquistas na área do conhecimento estejam à disposição de todos. No caso do Brasil, o conhecido abismo existente entre os ricos e os pobres de sua população ajuda a explicar e a ampliar a situação de "exclusão cognitiva" existente nesse país, quer se trate do contexto de produção quer se trate da aplicação do conhecimento.

\subsubsection{O que fazer?}

Foi dito acima que este tópico trabalha com a premissa de que o homem é, por essência, livre. De modo que, quando por alguma razão alguém é privado de exercer em plenitude sua liberdade, o que estará em risco é a sua própria humanidade. Deve-se ter em mente também que essa liberdade é devedora da democratização do conhecimento seja em seu contexto de constituição seja em seu contexto de aplicação. Agora, é o momento de buscar um caminho que possibilite avançar na realização histórica de tal democratização.

Acreditamos que a teoria do agir comunicativo elaborada por Habermas pode ser esse caminho. Nesse sentido, seu potencial é enorme. Suas contribuições poderão ser bastante úteis a fim de fazer avançar os debates epistemológicos em nossos dias. Começamos este tópico citando o texto de Kant sobre a llustração. No que diz respeito ao núcleo dos ideais da Aufklärung, Habermas se liga ao filósofo de Königsberg, dado que a teoria crítica habermasiana quer contribuir com o esclarecimento dos homens.

Considere-se aqui que para Kant o homem é um ser dotado de razão. Portanto, capaz de conhecer a si mesmo e o mundo; capaz de transformar a si mesmo e o mundo; e a primeira grande mudança que ele deve realizar, através do uso de sua razão, é a própria emancipação. Para Habermas, não é diferente. $O$ homem também é entendido como ser de razão e sua emancipação virá através do uso da razão. A diferença é que, em Kant, a razão é vista a partir de um contexto monológico (subjetivo) e, em Habermas, ela é considerada em um contexto dialogal (intersubjetivo).

Em seu livro Erkenntinis und Interesse (Conhecimento e interesse), Habermas vai apresentar suas teses a respeito dos interesses condutores do conhecimento, dentre eles o filósofo trata do interesse por emancipação. Para nosso autor não satisfaz apenas levar a pessoa a ser capaz de pensar, é preciso levá-la a dialogar (1973: 175)3. "Dialogar", em Habermas, é um termo mais rico do que possa parecer à primeira vista. Basta ter em mente, por exemplo, o que ele chama de "condições ideais de diálogo".

Segundo Habermas, sua teoria crítica ultrapassa a filosofia da consciência (monológica, como vimos $)^{4}$. Ele vai propor uma reflexão crítica sobre o contexto de constituição e de aplicação do conhecimento. Em Wozu noch Philosophie (Para que ainda filosofia), nosso autor vai nos dar o pano de fundo de suas reflexões a esse respeito, a saber: a llustração.

3. Aqui é possível uma aproximação entre a posição de Jürgen Habermas e o que defende Carl Rogers com suas idéias a respeito do aluno. Para Rogers, na verdade, a escola não recebe um "aluno", recebe uma "pessoa". Assim, tudo o que pensarmos em termos de ensino/aprendizagem, deve ser feito pressupondo esta afirmação de Carl Rogers. Ora, levar alguém a "dialogar" como quer Habermas, somente será possível se este "alguém" for considerado como pessoa, isto é: um ser com direitos e deveres; dotado de razão e sentimentos; com potencial para aprender e ensinar; sujeito livre, enfim. A esse respeito vale conferir ROGERS, Carl Ransom. (1988). Tornar-se pessoa. São Paulo: Martins Fontes.

4. VASCONCELOS, Francisco Antonio de. (2008). Habermas e o conteúdo irrenunciável da modernidade. Vila Velha: Quatro Irmãos, p. 65-74. 
De acordo com Habermas, o grande erro da Filosofia Social atual foi ter seguido o caminho do monólogo. O prejuízo por essa escolha errada foi reduzir seu campo de relacionamento apenas ao agir instrumental (Vasconcelos 2007: 38). Em Theorie und Praxis (Teoria e práxis) ele sugere que a saída para o problema reside no agir comunicativo, pois este está situado no plano das interações do entendimento entre sujeitos capazes de falar e de agir (1971: 15).

Certamente, o pensamento de Habermas representa uma substancial contribuição no que toca à democratização do conhecimento. Acesso de todos a participar do processo de constituição do conhecimento e acesso de todos a participar do processo de aplicação desse conhecimento já construído, pois "no processo do conhecimento não existe os que sabem mais e os que sabem menos, existem apenas participantes" (1971: 45).

\section{Conclusão}

Comecemos esta conclusão com uma citação longa, mas pertinente, do filósofo argentino Mario Bunge. Diz ele:

Enquanto os animais inferiores só estão no mundo, o homem trata de entendê-lo. Sobre a base de sua inteligência imperfeita, porém perfectível do mundo, o homem tenta assenhorearse para fazê-lo mais confortável... Por meio da investigação científica, o homem alcançou uma reconstrução conceitual do mundo que é cada vez mais ampla, profunda e exata.

Um mundo é dado ao homem; sua glória não é suportar ou desvalorizar este mundo, mas enriquecê-lo construindo outros universos... trata logo de remodelar este ambiente artificial para adaptá-lo a suas próprias necessidades animais e espirituais: cria assim o mundo dos artefatos e o mundo da cultura (1998: 11).

Destaquemos três afirmações de Bunge. Ele diz que o "homem" busca assenhorear-se do mundo com o intuito de fazê-lo mais confortável; que o "homem" avança cada vez mais na reconstrução $:: 38::$ conceitual do mundo e, finalmente, que deve enriquecê-lo.

O autor argentino tem razão em cada uma dessas afirmações. O problema é que o termo por ele utilizado, "homem", não comporta de fato todos os seres humanos do planeta. Pelo contrário, a boa parte da população do globo simplesmente não se dá o direito a uma existência proativa quando o assunto é conhecimento: uma vez que foi excluída do processo responsável pela produção do conhecimento ou nele tomando parte de modo, consideravelmente, inexpressivo. Não bastasse ser posta à margem desse processo, ainda lhe é negado o acesso aos bens advindos do conhecimento conquistado e acumulado pelo homem. De modo que para essas pessoas o mundo não se tornou mais confortável; nem elas estão podendo avançar na produção conceitual do mundo; por fim, está sendo vetado a essas pessoas o direito a colaborar de modo mais eficaz para o enriquecimento do mundo.

É preciso, então, mudar esse quadro: por um lado, fazendo com que todos possam participar de modo proativo do desenvolvimento e do aperfeiçoamento da riqueza intelectual da humanidade; por outro, possibilitando a todos a oportunidade de utilizar os bens provenientes do desenvolvimento cognitivo elaborado ao longo da história.

Certamente, para termos uma educação capaz de emancipar a pessoa precisamos chegar a essa situação de democratização do conhecimento, também precisamos contar com uma teoria da educação que tenha, dentre outras, as seguintes características:

- Como quer Edgar Morin, seja dialógica para juntar coisas que aparentemente estão separadas (a razão e a emoção, o sensível e o inteligível, as Ciências Humanas e as Ciências da Natureza, etc); que conceba as pessoas como seres complexos, isto é, $100 \%$ natureza e $100 \%$ cultura; que entenda a cultura como transdisciplinar.

- Como sugere Carl Rogers, aceite formar pessoas e não simplesmente instruir alunos; que não deixe a ditadura do conteúdo sufocar a liberdade do aprender.

- Como deseja Howard Gardner, considere que as pessoas são diferentes umas das outras e que trabalhe com essas diferenças; considere o conhecimento um bem e não apenas um conjunto de informações; que ajude o aluno a aprender com compreensão. 
- Como defende B. F. Skinner, que sempre esteja aberta ao novo, rejeitando as verdades eternas; que propicie um aprendizado suave, gostoso e gradual; que faça com que o aluno se sinta atraído pela escola, porque nela ele consegue encontrar as mais fortes razões para se manter aprendendo, mesmo fora da escola;

- Inspirando-se em Henri Wallon, procure ver o aluno de modo mais integrado.

- Como propõe Celestin Freinet, possua um profundo respeito pelo aluno; que proporcione o surgimento de um tipo de escola capaz de despertar interesse no aluno, motivando-o a fazer parte dessa escola; que possibilite um tipo de relação entre professor e aluno, na qual o aluno interaja com o professor.

- Enfim, como quer Paulo Freire, seja uma teoria da educação que leve a uma educação como prática de liberdade ${ }^{5}$, uma pedagogia da autonomia ${ }^{6}$, na qual "[...]homens e mulheres transformados em objetos emergirão através de um processo dialógico como sujeitos de sua própria história”.7

Sendo assim, a teoria do agir comunicativo de Habermas, devedora da llustração e essencialmente teórico crítica, será um referencial de grande valor para uma educação verdadeiramente comprometida com a autodeterminação da pessoa.

\section{A autodeterminação e a educação em Habermas}

No Kleine politische Schriften (I-IV) de 1981, Habermas trata de dizer qual é a final o projeto da modernidade ${ }^{8}$.

O passo seguinte é afirmar que esse projeto ainda está por ser concretizado, ou seja, é um projeto que assume o status de inacabado (unvollendetes), para usar a terminologia de Habermas.

Em 1985, foi publicada uma das mais importantes obras do filósofo de Düsseldorf, trata-se de $O$ discurso filosófico da modernidade 9 . As palavras que abrem o prefácio dessa obra são as seguintes: «Modernidade - um projeto inacabado...». Aí, temos Habermas citando o tema do discurso que fora proferido por ele em 1980, quando recebeu o Prêmio Adorno. Isso, certamente é suficiente para que se perceba o quanto essa temática é importante para Habermas. Como ele mesmo disse em 1985, tal tema não mais o deixou.

\subsection{A teoria do agir comunicativo habermasiana e a autodeterminação}

Considerando os pontos principais da teoria do agir comunicativo, tal como a entende Habermas, queremos mostrar que ela está habilitada a contribuir para a autodeterminação da pessoa humana. Portanto, esperamos, no final desse tópico, responder em que consiste a autodeterminação e como um indivíduo pode chegar a atingi-la, tornando-se uma pessoa autodeterminada de acordo com o pensamento de Habermas.

Para isso, (I) tomamos como ponto de partida a afirmação habermasiana de que a modernidade é, de fato, um projeto ainda não realizado.

Vejamos como Habermas conduz a defesa do projeto racionalístico da modernidade. Neste contexto se insere o confronto com Heidegger, com o pós-estruturalismo francês, com pragmatismo relativista de Rorty e com a reflexão ética e, mais em geral, no confronto de Habermas com o pensamento contemporâneo, como a hermenêutica, a filosofia analítica e o marxismo.

5. Freire, Paulo. (2003). Educação como prática da liberdade. 27.ed. São Paulo: Paz e Terra. Esse livro foi escrito após a queda de João Goulart, entre uma prisão e outra e concluído no exílio. Nele está presente, no essencial, todo o projeto pedagógico do pedagogo pernambucano, sintetizado no próprio título do livro.

6. Sobre isto, deve-se conferir o seu livro (2003). Pedagogia da autonomia: Saberes necessários à prática educativa. 28. ed. São Paulo: Paz e Terra.

7. Streck et al. (2001). Paulo Freire: ética, utopia e educação. Petrópolis: Vozes, p. 9.

8. Habermas, Jürgen. (1981). Kleine politische Schriften (I-IV). Frankfurt am Main: Suhrkamp, p. 452-454.

9. Habermas, Jürgen. (2002). O discurso filosófico da modernidade. Tradução de Luiz Sérgio Repa e Rodnei Nascimento.

São Paulo: Martins Fontes. 
A fase da história da filosofia que se abre com a crise do hegelianismo é, de acordo com Habermas, aquele do pensamento pós-metafísico ${ }^{10}$, cuja marca principal é a historicização da razão, que se recusa a associar à racionalidade características como a pureza, a unidade e a imutabilidade. A ontologia clássica (de matriz grega) e a filosofia da consciência são os produtos de uma concepção metafísica da razão.

A noção hegeliana de saber absoluto é o último episódio da aventura metafísica ocidental: a tentativa extrema de manter unidas razão absoluta e história, imutabilidade e movimento. A filosofia contemporânea rompe com esse paradigma. Ela é essencialmente historicista, renuncia a uma razão auto-suficiente e desvela as relações desta com o não puramente racional: a práxis, a existência, o corpo, a linguagem, a tradição. A guinada lingüística da filosofia se insere nesse contexto.

Essa epocal mudança de horizonte filosófico põe no pensamento contemporâneo uma questão importante: a relação com a modernidade e com seu conteúdo normativo. A rejeição à metafísica e à sua última expressão, a filosofia do sujeito, conhece no pensamento contemporâneo uma variante que, segundo Habermas, leva a Nietzsche e que identifica totalmente a modernidade com a centralidade do sujeito.

À rejeição do subjetivismo segue a rejeição da própria modernidade e de seu conteúdo normativo.

Em O discurso filosófico da modernidade, Habermas apresenta o conceito de modernidade elaborado por Hegel (Habermas 2002: 35-36.) e lembra que esse conceito, tal como Hegel o entendia, continuou sendo aceito até Max Weber (8). A questão que será colocada por Habermas é a de se saber se esse conceito hegeliano realmente não tem mais como se manter, ou se, pelo contrário, ele ainda continua sendo válido.

O passo seguinte (II) é explicar que essa validade ocorre não mais através de uma razão centrada no sujeito monológico da filosofia da consciência, mas, ao contrário, ela se manterá por meio de uma razão dialógica centrada na intersubjetividade. Essa inspiração, Habermas vai buscar no jovem

::40:: Hegel. Este havia encontrado um caminho, mas se recusou a trilhá-lo, a saber: a comunicação. Esta aponta para "[...] uma intersubjetividade ilesa que, de início, o jovem Hegel tivera em mente como totalidade ética" (2002: 468). Isto nos levará a dois conceitos valiosos para a filosofia de Habermas, a saber: a ação comunicativa e o mundo da vida.

Quanto à ação comunicativa, vale lembrar que a partir dos anos 70 o pensamento de Habermas realiza uma guinada lingüística. Isso aparece, sobretudo, no que diz respeito à estrutura da racionalidade. Tudo isso vai desembocar na teoria do agir comunicativo de Habermas.

Essa teoria, por um lado, está ligada à teoria da racionalidade elaborada por Habermas, na medida em que esta última conduz a uma razão comunicativa e a uma pragmática universal; por outro lado, relaciona-se com uma teoria da ação social, que segundo Habermas, deveria permitir lidar com questões como a racionalização social de Weber, utilizando novos caminhos.

Mas, vale lembrar que a noção de racionalidade comunicativa além de ser de natureza sociológica é também de natureza filosófica. A idéia de razão comunicativa está, em Habermas, no centro de uma filosofia que quer ser universalística, anticética e pós-metafísica. A filosofia deve, para ele, assumir o papel de guardiã da racionalidade, pondo em luz as características estruturais da racionalidade, as quais, diga-se de passagem, encontram-se na própria estrutura da fala que as pessoas empregam no quotidiano para se comunicar.

Assim, o horizonte, no qual o pensamento de Habermas quer situar-se, é a guinada lingüística da filosofia contemporânea, realizada pela filosofia analítica e pela filosofia hermenêutica. A linguagem, portanto, substitui a consciência enquanto conceito central do conhecimento filosófico. Transpondo tudo isso para o campo do agir humano, teremos a linguagem como solo sobre o qual Habermas irá erguer o seu pensamento ético. 
Quanto ao mundo da vida, considere-se que é composto por três esferas. A primeira é a esfera da cultura; a segunda, a da personalidade e, finalmente, a esfera da sociedade.

No início de 0 discurso filosófico da modernidade, precisamente na página 469 Habermas elenca três itens que representam o conteúdo normativo da modernidade, tais sejam:

A consciência de si;

A auto-realização;

A autodeterminação.

Mais adiante, na página 479 ele escreve que "[...] a consciência de si retorna na forma de uma cultura tornada reflexiva; a autodeterminação, em valores e normas generalizados, e a auto-realização, na individuação progressiva dos sujeitos socializados».

Em relação a esses valores e a essas normas, é o próprio Habermas que diz que eles devem ser fundamentados discursivamente (2002: 478), sem pressões ${ }^{11}$. o conteúdo normativo da modernidade, constituído por idéias tais como validade universal do conhecimento e das normas, de igualdade e respeito recíproco resultam diretamente das estruturas relativas à cultura, à sociedade e à personalidade das obrigações comunicativas que se originam no mundo quotidiano da vida.

$\mathrm{Na}$ intersubjetividade comunicativa cada um assume a posição de um "Eu" individual e levanta pretensões universais de validade (verdade ${ }^{12}$, justeza e sinceridade), estabelece uma relação frontal paritária com um "Tu". Desta estrutura performativa, é possível extrair os valores que constituem o lado construtivo da modernidade.

A ética para Habermas é inerente à comunicação e eminentemente comunicativa. Para ele são comunicativas as ações nas quais os participantes coordenam de comum acordo os seus planos de ação. Como por diversas vezes aparece em sua obra de 1981 intitulada Teoria do agir comunicativo, a ética é um tipo de agir prioritariamente orientado ao entendimento.

O entendimento ético, por sua vez, vem através da satisfação discursiva das pretensões de validade e por uma referência a um mundo próprio dos agentes morais. Segundo Habermas, é sobre estas bases que se torna possível o acordo em cima do qual se sustentará o próprio acesso ao jogo-ética, que buscará constantemente incluir no discurso àqueles que estão à margem do espaço público, ou seja, fora do processo de tomada de decisões ${ }^{13}$.

\subsection{Princípios D e U}

Aqui (III) chegamos ao Princípio do Discurso e ao Princípio de Universalização. O primeiro é formulado do seguinte modo: "Podem pretender validade apenas as normas que encontram (ou podem encontrar) o consenso de todos os sujeitos envolvidos enquanto participantes de um discurso prático" (Habermas 1986: 19). O Princípio do Discurso conduz ao discurso prático, à argumentação moral.

Na verdade, o princípio da ética do discurso atribui a fundamentação das normas ao discurso prático. O problema da validade dos juízos morais aponta para a questão da lógica do discurso prático.

11. Para Habermas, a única pressão válida é a do melhor argumento, utilizado num discurso no qual todos os interessados devem poder participar. Para Bourdieu e Passeron, ao contrário, os grupos dominantes reproduzem nas classes subalternas sua visão de mundo (seus valores, suas normas, etc) de acordo com os interesses desses mesmos grupos detentores do mando, através da ação pedagógica; não precisando recorrer ...à pressão externa e, em particular, à coerção física. BOURDIEU, Pierre. e PASSERON, Jean-Claude. (1996). La Reproducción: Elementos para una teoria del sistema de enseñanza. México: Fontamara, p. 76.

12. A posição de Habermas sobre a verdade faz lembrar as palavras de Educar em la era planetária: "[...] não se nega a verdade, mas o caminho da verdade é uma busca sem fim”. Morin, E. ; Civrana, E.R. e Motta, R.D. (2002). Educar en la época planetária: El pensamento complejo como método de aprendizage en el error y la incertidumbre humana. Salamanca: Unesco/Universidad de Valladolid, p. 24.

13. Habermas, J. (2002). A reconciliação por meio do uso público da razão. In: Idem. A inclusão do outro: Estudos de teoria política. São Paulo: Edições Loyola, p. 61-68. A respeito do significado de espaço público ao longo da evolução do pensamento de Jürgen Habermas, será de grande proveito a leitura de Silva, Felipe Carreira da. (2002). Espaço público em Habermas. Coleção Estudos e Investigações, n²6. Lisboa: Instituto de Ciências Sociais. 
Neste ponto, encontramos o segundo princípio, o Princípio de Universalização, definível como a regra de argumentação nos discursos práticos. Eis como Habermas o formula: "Nas normas válidas, devem poder ser aceitas por parte de todos, sem constrições, os resultados e as conseqüências secundárias que derivam de sua universal observância para a satisfação dos interesses de cada um" (1986: 19).

O Princípio do Discurso, que é o princípio da ética do discurso, leva ao Princípio de Universalização, que é para Habermas, o princípio moral fundamental, o elemento constitutivo do ponto de vista moral.

A ética do discurso introduz o princípio formal da discussão pública entre indivíduos livres e iguais, substituindo o tribunal da consciência moral privada, o que a torna, nesse aspecto, diferente da moral kantiana.

Habermas assinala ao princípio de Universalização uma função metodológica como regra de argumentação no âmbito do discurso prático. Esse é o pressuposto necessário de uma ética cujo critério é o discurso, a interação na qual os interlocutores se submetem à correção do melhor argumento.

No projeto de Habermas, o Princípio de Universalização obriga a cada um a realizar uma universal troca de papéis, a que Habermas assinala o valor de um empreendimento realizado por indivíduos numa argumentação moral real da qual eles participam como livres e iguais, e no curso da qual não se limitam a registrar e a somar as suas preferências, mas perseguem livremente o objetivo de um entendimento intersubjetivo. A imparcialidade das normas será verificada quando elas, incorporando visivelmente um interesse comum a todas as pessoas envolvidas, podem contar com o consenso universal.

O Princípio de Universalização deve ser entendido, por isso, como regra de argumentação que torna possível um acordo nos discursos práticos, toda vez que as questões materiais possam vir

$\because 42::$ reguladas nos interesses paritários de todos os sujeitos envolvidos.

Ele subentende a universal competência comunicativa de sujeitos em fornecer e confrontar bons argumentos quando se trata de resolver os cotidianos conflitos de interesses e de aplainar os dissensos. O Princípio de Universalização é, portanto, regra de uma ação inter-humana que tem por objetivo um acordo baseado em razões, não derivado do calculo estratégico de indivíduos egoístas.

Habermas faz valer a idéia moderna e iluminista da igualdade de respeito dos sujeitos que participam do discurso, e do direito a igual consideração do seu entendimento do bem. Para Habermas, Mead dá uma guinada teórica no argumento de Kant: O fundamento da validade de uma norma é que ela possa ser aceita com boas razões por todos os interessados. Só assim compreendida, isto é, como algo que é fundamentado sobre razões para todos os interessados, a universalidade pode ser considerada critério de validade da norma moral.

Na leitura habermasiana, Mead substitui, portanto, o imperativo categórico pela formação discursiva da vontade. A universalização que o imperativo categórico exigia do sujeito isolado, agora é realizada de modo comunicativo pela intersubjetividade.

Uma vez que a idéia de um entendimento racionalmente motivado já está instalada na estrutura da linguagem, isto não é uma mera exigência da razão prática, mas está inserida na reprodução da vida social.

À medida que a integração social deixa de ser articulada sob bases religiosas, e passa a ser articulada de modo crescente sobre bases comunicativas, o ideal da comunidade ilimitada de comunicação atua cada vez mais de modo eficaz sobre a realidade social comunicativa empírica. Princípios universalísticos do direito e formação discursiva da vontade se impõem no processo democrático onde a fundamentação da legitimação é remetida a pretensões de validade instaladas na linguagem. 
A comunidade ideal de comunicação contém não apenas o projeto prático moral de uma formação racional discursiva da vontade, mas também o projeto expressivo de uma relação não alienada com a própria subjetividade que permita uma empática auto-apresentação recíproca.

Habermas tendo iniciado uma temática centrada sobre a dialética teoria-práxis, de base hegelianomarxiana, transfere-se para o terreno dos paradigmas do agir comunicativo, passando pelo tema da situação lingüística ideal, com a idéia de que na própria estrutura da linguagem está imanente o telos do entendimento.

Da fase da auto-reflexão da consciência a respeito da natureza dos interesses que guiam o conhecimento presente em seu trabalho de 1968 intitulado Conhecimento e interesse, chega-se ao anúncio do abandono do paradigma da consciência e do sujeito cognoscente a favor do paradigma da intersubjetividade comunicativa radicada no mundo da vida, como testemunha sua célebre obra de 1981 (Teoria do agir comunicativo).

Durante esse percurso a bagagem intelectual de Habermas se enriqueceu, por um lado, com a aquisição de novos motivos; por outro, com o abandono de inspirações anteriores. Pode-se destacar a sua relação com o marxismo, por exemplo. Sempre mais explícita e articulada é a tomada de distância em relação à teoria crítica de Adorno e Horkheimer. Muitas são as críticas dirigidas ao pensamento de Habermas. Vale destacar o que diz Tugendhat sobre a realização do consenso: É absurdo. Ou a opinião de Deleuze e Guattari a respeito da relação entre Filosofia e diálogo: A Filosofia tem horror ao diálogo.

Porém, num contexto de idéias caracterizado por uma severa censura ao iluminismo e ao núcleo normativo da modernidade e pelo predomínio de posições céticas e relativistas, este é um mérito considerável que justifica toda a nossa simpatia. Uma filosofia que aceita plenamente o desafio de uma reflexão sobre a racionalidade; uma reflexão que para alguns pode parecer ambiciosa; que pode apresentar-se aporética, porém jamais renunciável. Este nos parece um grande mérito da obra de Habermas; particularmente, de sua ética do discurso.

Caso a racionalidade não venha a ser pensada a partir do paradigma de uma razão centrada em si mesma, essa racionalidade será identificada com a capacidade dos que participam de um processo interativo de se orientarem por pretensões de validade que são reconhecidas intersubjetivamente. Tal racionalidade está presente na estrutura mesma da linguagem humana. Nesse sentido a manipulação instrumental-cognitivo-prática da natureza objetivada aparece como momento derivado da razão, que na modernidade foi emancipada da razão comunicativa.

Então, para recuperar a práxis racional do homem, é preciso reintegrar essa razão cindida; mas, para isso, será necessário uma mudança de paradigma: deixar a razão centrada no sujeito, que caracteriza a moderna filosofia da subjetividade, colocando em seu lugar a razão comunicativa. Isto permitirá nos levar a uma práxis de transformação, que construirá uma cidade realmente humana (Oliveira 1993: 92).

Para Habermas, constitui um erro descartar pura e simplesmente a modernidade. Ele opta por manter-se no solo da modernidade (com sua teoria do agir comunicativo), esforçando-se por salvar aquele conteúdo da modernidade que não deve ser rejeitado. Para a manutenção desse conteúdo normativo como, por exemplo, autodeterminação do sujeito, terá um papel significativo a mudança de paradigma que conduzirá aos conceitos de "mundo da vida" e "razão comunicativa", por um lado; e "Princípio do Discurso" e "Princípio de Universalização", por outro .

A ética do discurso salva o individualismo iluminista lutando por sua autodeterminação.

De tudo isto, afirmamos: autodeterminado é todo indivíduo que vive sob valores e normas estabelecidos e fundamentados a partir do Princípio de Universalização e do Princípio do Discurso.

Esses dois princípios lançam luz sobre nossa reflexão a respeito da educação:

a) O Princípio de Universalização: Uma vez estabelecido as regras (fruto do esforço de todos), faz-se necessário levá-las a sério; assumindo suas conseqüências. Aqui estamos falando de 
responsabilidades: responsabilidade para com a vida, a história, o meio ambiente, a sociedade, o agir político, as gerações futuras, a pessoa do outro, etc;

b) O Princípio do Discurso: As decisões devem surgir de uma discussão da qual todos devem poder participar. Na prática, salta aos olhos o quanto isto é difícil de acontecer. O que nos leva ao passo seguinte: é preciso romper as barreiras existentes; derrubar os muros que separam a tantos do direito a exercer sua cidadania, isto é, a tomar parte no espaço público. Faz-se necessário unir esforços contra os mecanismos geradores de exclusão social, econômica, jurídica, cognitiva, etc. A respeito da exclusão cognitiva pode-se perguntar com Betellheim como o aluno pode aprender quando tem:

[...] um estômago vazio pedindo comida, um dente molar estropiado que dói, um corpo debilitado por falta de descanso, uma mente angustiada que se pergunta que tipo de violência estará aguardando por ela na rua ou em casa, para não dizer nos corredores da escola. A pressão imediata de todas estas coisas distrairá e deprimirá a criança e a impedirá de aprender (1982: 22-23).

\section{Conclusão}

O que foi dito até agora, leva-nos a pensar a Educação como prática da cidadania e cidadania significando participação no espaço público. A esse respeito, vale a pena conferir o que diz a Profa. Santos: "[...] educar para a cidadania não pode se restringir à conscientização dos direitos e deveres, ...mas requer o reconhecimento da necessária competência político/social ...que possibilite a participação no espaço público das negociações" (2003: contracapa).

A autora inspirada no pensamento de Habermas prossegue:

Compreendendo a cidadania como concernente ao ingresso na comunidade ético-discursiva (capacidade de participar nos negócios públicos), enfatiza a importância da escola no desenvolvimento da competência comunicativa, de modo a municiar o cidadão para participar no debate público das negociações (2003: orelha).

No início deste trabalho, comprometemo-nos a dizer o que significa a autodeterminação e o que fazer para realizá-la. A primeira destas questões já foi respondida. A segunda tem a ver com o fundamento da Educação. Então, qual deve ser, hoje, seu fundamento? Sobre qual base, na atualidade, as questões educacionais devem ser colocadas? Parece sensato afirmar que a resposta é o direito de todos a tomar parte no espaço público. Para que isto se concretize, conforme foi visto até aqui, o pensamento de Jürgen Habermas sobre o agir comunicativo tem muito a contribuir.

\section{CONSIDERAÇÕES FINAIS}

A indignação diante da miséria que massacra as camadas mais empobrecidas; a certeza de que mesmo as pessoas mais "simples" possuem conhecimentos necessários ao resto da sociedade; a convicção que a liberdade humana é algo sagrado e que quem a desrespeita comete sacrilégio, tornando-se é culpado de praticar uma monstruosidade; a certeza que o respeito ao ser humano é uma necessidade para um convívio social saudável; o convencimento de que a democracia é um bem a ser preservado por todos; a certeza que a escola deve, efetivamente, estar aberta a todos; e, finalmente, a aposta no diálogo como método foram idéias relevantes para a pesquisa.

Mas o que fazer para pôr fim à miséria que humilha e tenta desumanizar a tantos? Como valorizar os saberes populares, integrando-os de modo justo ao conjunto da cultura da sociedade? Quais passos devem ser dados a fim de que se possa proteger, de fato, a liberdade humana tanto no espaço público quanto no privado? Quais procedimentos devem ser empreendidos para que se crie a cultura do respeito ao outro? O que fazer para fortalecer a democracia? Quais caminhos deve-se trilhar a fim de que se tenha uma escola, verdadeiramente, democrática? Como conceber o diálogo, a fim de se poder avançar no fortalecimento da democracia e na autodeterminação da pessoa? 
Aqui, essas questões foram norteadoras. Esta pesquisa as considerou partindo do pensamento de Jürgen Habermas, sobretudo, de sua teoria do agir comunicativo aplicada à educação, tendo em vista a elaboração de um tipo de agir pedagógico que, efetivamente, contribua para a autodeterminação da pessoa.

A pesquisa como um todo apontou para a necessidade de se utilizar a prática da "participação" como elemento fundamental a fim de que a escola possa, de fato, converter-se em um instrumento de transformação da realidade, leia-se aqui, para fortalecer a democracia e atingir a realização do ideal de emancipação do indivíduo.

Ela desvela um quadro no qual se constata vários pontos frágeis seja no que diz respeito à própria democracia seja no que toca à autodeterminação da pessoa. Esses pontos críticos se sobressaem ainda mais quando se leva em conta o papel reservado à escola como meio para ajudar a realizar esses dois ideais.

No que se refere às fragilidades da democracia, pode-se destacar a persistência da histórica concentração de renda no Brasil ${ }^{14}$ responsável, por si só, por uma imensidão de problemas sociais, políticos e culturais; a discriminação (às vezes velada outras vezes exposta) de natureza racial, regional e/ou econômica com a qual, infelizmente, convivemos neste país; o desenvolvimento econômico regional, marcadamente, desigual; o acesso elitizado seja no que se refere ao processo de produção seja no que diz respeito ao processo de aplicação do conhecimento; e, para não nos estendermos em demasiado, podemos mencionar as dificuldades diretamente ligadas à escola, ou seja, carências de salas de aula, prédios escolares em estado de manutenção ruim, escolas não informatizadas, falta de corpo docente, de corpo técnico, baixos salários, problemas da gestão em algumas prefeituras que, dentre outros prejuízos, resulta na falta de merenda escolar para as crianças da rede municipal de ensino ${ }^{15}$.

Sobre as dificuldades no campo da autodeterminação da pessoa, deve-se ter presente que todos os pontos mencionados no parágrafo anterior trabalham contra a efetivação do projeto de emancipação do indivíduo, direto ou indiretamente. Em todo caso, vale aqui destacar um fato importante que depõe contra a autodeterminação da pessoa: a força que as elites ainda possuem na sociedade brasileira, controlando o Estado e a economia. Com estes dois instrumentos de poder em suas mãos, ela infelizmente consegue ter um alto grau de influência na elaboração da visão de mundo presente no restante da sociedade ${ }^{16}$.

O fato do indivíduo nascer numa sociedade que, evidentemente, já possui um Direito estabelecido, uma moral elaborada, uma tradição epistêmica em atividade, princípios religiosos constituídos, enfim, um modo de se relacionar com os outros de sua espécie e de interagir com o mundo em sua volta, de lidar com o transcendente, com a história, etc, impõe a este indivíduo um certo nível de dependência. Mas isto em si não é um mal, ao contrário é algo totalmente natural. A dificuldade surge quando essas ações são fortemente influenciados por uma pequena parcela da sociedade (as elites dominantes) e, conseqüentemente, impostas ao restante da sociedade sendo por estas últimas assimiladas de modo acrítico.

A escola deve ser um agente transformador desta situação, conforme foi lembrado no decorrer deste trabalho. Entretanto, observa-se que, no que diz respeito a isso, ela está em débito, não está obtendo o êxito esperado no desempenho dessa sua tarefa. Uma das explicações é o fato, já destacado por Karl Marx, Antonio Gramsci e tantos outros, da escola ser utilizada pelas classes hegemônicas da sociedade a serviço da manutenção e propagação da ideologia dessas elites. O que fazer então? Deve-se dar razão a Ivan Illich e fechar as escolas? Não, claro que não. De fato, como defende Paulo Freire para que a escola mude, primeiro será necessário acreditar que a transformação é possível.

14. Citamos este país posto que, durante a realização desta pesquisa, foi a situação vivenciada neste país a que tivemos como referência.

15. É preciso que se ressalte que essa política do Governo Federal de levar "merenda" às escolas é extremamente benéfica e vem melhorando ano a ano.

16. O que Lev Vigotsky diz a respeito da sociogênese lança luz sobre o que foi colocado. 
Sobre isto, estamos de acordo com o pedagogo pernambucano. A mudança é possível, sim. E mais, o Brasil vem melhorando, embora seja verdade que essa mudança venha ocorrendo a passos lentos. A título de exemplo desta transformação, pode ser citada a consciência, que vai se generalizando, de que a escola precisa converter-se, ela mesma, numa comunidade democrática para que ela possa ser, de modo eficaz, um agente da democratização da sociedade.

Certamente, a participação é via a ser trilhada, se quisermos construir uma escola diferente, isto é, uma escola efetivamente a serviço da implementação de uma sociedade democrática e da autodeterminação da pessoa. As dificuldades na obtenção dessa meta são proporcionais ao interesse do corpo docente, do corpo discente, seus pais e/ou responsáveis, do corpo técnico, da direção da escola, da comunidade local na qual a escola está situada, do Estado, etc em cumprir o papel que the é reservado quando se trata da escola.

A participação de todos para melhorar nossas escolas, eis aí o que sugerimos como contribuição mais efetiva desta pesquisa. Certamente, haverá quem se levante, apressadamente, para dizer que nunca teremos participação plena dos agentes mencionados no parágrafo anterior. É verdade que o grau de participação nunca será pleno, porém este fato não invalida a conclusão desta pesquisa em relação ao que foi dito sobre a força transformadora da participação como meio, segundo foi esclarecido acima.

Carreira da Silva defende a idéia de que desde 1962, com a publicação de Mudança estrutural da esfera pública, o essencial das teses de Jürgen Habermas se mantém. Afirma ele: "Isto vale não só para nosso fio condutor - o espaço público ${ }^{17}$-, mas também para o conjunto de idéias e princípios que definem e caracterizam o edifício teórico de Habermas: a pretensão de reconstrução do legado racionalista, igualitário e universal do iluminismo, o ideal normativo de uma 'situação ideal de discurso', a noção de consenso racional argumentativamente alcançado" (2002: 14).

As propostas da modernidade são utopias necessárias, inspiradas em problemas sócio-políticoeconômicos reais que ainda persistem no século XXI, e, aqui e ali, infelizmente se agravaram de

$:: 46::$ modo substancial. Portanto, oxalá que as gerações do próximo século tenham a alegria de não conviverem com essa espécie de problemas, que não venham a experimentá-los. Oxalá, ainda, que as gerações do século vindouro venham a nos agradecer, a nós do século XXI, por termos conseguido resolver esses problemas, realizando desta forma o projeto da modernidade. Assim, se esta utopia se tornar realidade, no século XXII haverá uma sociedade verdadeiramente democrática e nela as pessoas serão, efetivamente, emancipadas, autodeterminadas. Então, sem dúvida, essa sociedade será uma sociedade pós-moderna.

\section{ÍNDICE DE FONTES}

\section{SECUNDÁRIAS}

\section{Bibliografia}

BETELLHEIM, B. (1982): Educación y vida moderna. Estudios y Ensayos. Barcelona: Grijalbo.

BOURDIEU, P.; PASSERON, J-C. (1996): La Reproducción: Elementos para una teoria del sistema de enseñanza. México: Fontamara.

FREIRE, P. (2003): Educação como prática da liberdade. (270) ed. Rio de Janeiro: Paz e Terra. (2006): Pedagogia da esperança: Um reencontro com a Pedagogia do oprimido. $\left(13^{\circ}\right)$ ed. Rio de Janeiro: Paz e Terra.

(2003): Pedagogia da autonomia: Saberes necessários à prática educativa. $\left(28^{\circ}\right)$. ed.

São Paulo: Paz e Terra.

HABERMAS, J. (2001): A constelação pós-nacional: Ensaios políticos. Tradução de Márcio Seligmann-Silva. São Paulo: Littera Mundi. 
. (2002): A inclusão do outro: Estudos de teoria política. Tradução de Gorge Spenber e Paulo Astor Soethe. São Paulo: Loyola.

Guanabara.

(1987): Conhecimento e interesse. Tradução de José N. Heck. Rio de Janeiro: Editora

(2003): Consciência moral e agir comunicativo. Rio de Janeiro: Tempo Brasileiro.

(1985a): Moderne und postmoderne Architektur. In. Die neue Unübersichtlichkeit.

Frankfurt am Main: Suhrkamp.

Main: Suhrkamp.

(1985b): Der philosophische Diskurs der Moderne: Zwölf Vorlesungen. Frankfurt am

. (1990): Die Moderne - ein unvollendetes Projekt: Philosophisch-politische Aufsätze (1977-1990). Leipzig: Reclam.

(1994): Direito e democracia: Entre facticidade e validade. Tradução Flávio B. Rio de

Janeiro: Tempo Brasileiro.

(1973): Erkenntinis und Interesse. Frankfurt am Main: Suhrkamp.

(1984): Erläuterungen zum Begriff des kommunikativen Handels. In. Vorstudien und

Ergänzungen zur Theorie des kommunikativen Handelns. Frankfurt am Main: Suhrkamp.

. (1986): Entgegnun. In. HONNETH, A. e JOAS H. (Org.). Kommunikatives Handeln.

Frankfurt am Main: Suhrkamp, pp. 327-353.

. (1981a): Kleine politische Schriften (I-IV). Frankfurt am Main: Suhrkamp.

Ie II.

(1981b): Theorie des kommunikativen Handelns. Frankfurt am Main: Suhrkamp, Vols.

Suhrkamp.

(1983): Moralbewußtsein und kommunikatives Handeln. Frankfurt am Main:

(1986): Moralität und Sittlichkeit: Treffen Hegels Einwände gegen Kant auch auf

Diskursethik zu?, In: Kuhlmann, W. (ed.) Moralität und Sittlichkei: Das Problem Hegels und

Diskursethik. Frankfurt am Main: Suhrkamp.

(2002): O discurso filosófico da modernidade. Trad. de Luiz Sérgio Repa e Rodnei

Nascimento. São Paulo: Martins Fontes.

(1990a): Para a reconstrução do materialismo histórico. Tradução de Carlos Nelson Coutinho. São Paulo: Editora Brasiliense.

(1990b): Pensamento pós-metafísico: Estudos filosóficos. Tradução Flávio Beno

Siebeneichler. Rio de Janeiro: Tempo Brasileiro.

. (1990c): Strukturwandel der Öffentlichkeit. Frankfurt am Main: Suhrkamp.

(2004): Verdade e justificação: Ensaios filosóficos. São Paulo: Loyola.

(1971a): Theorie und Praxis. Frankfurt Am Main: Suhrkamp.

(1971b): Wozu noch Philosophie. In HABERMAS, Jürgen. Philosophisch-politische

Profile. Frankfurt am Main: Suhrkamp, pp. 11-36.

KANT, I. (2004). Respuesta a la pregunta que és la ilustración? In. Filosofia de la historia: qué és la ilustración? La Plata: Caronte Filosofía.

MORIN, E.; CIVRANA, E.R.; MOTTA, R.D. (2002): Educar en la época planetária: El pensamento complejo como método de aprendizage en el error y la incertidumbre humana. Salamanca: Unesco/ Universidad de Valladolid.

OLIVEIRA, M.A. (1983): A ética do discurso: K.-O. Apel e J. Habermas. In: Ética e racionalidade moderna. Col. Filosofia. $\mathrm{N}^{\circ}$ 28. São Paulo: Loyola, pp. 9-39.

(1983): A crise da racionalidade moderna. In: Ética e racionalidade moderna. Col. Filosofia. № 28. São Paulo: Loyola, pp. 68-94.

Rogers, C.R. (1988): Tornar-se pessoa. São Paulo: Martins Fontes.

SANTOS, N.L. et ali. (2003): Cidadania no discurso da modernidade: Uma interpelação à razão comunicativa. Illhéus: Editora da UESC.

SIEBENEICHLER, F.B. (1989): Jürgen Habermas: razão comunicativa e emancipação. $\left(3^{\circ}\right)$ ed. Rio de Janeiro: Tempo Brasileiro.

SILVA, F.C. (2002): Espaço público em Habermas. Coleção Estudos e investigações, 26. Lisboa: Imprensa de Ciências sociais.

STRECK, D. et ali. (2001): Paulo Freire: ética, utopia e educação. Petrópolis: Vozes.

VASCONCELOS, F.A. (2008): Habermas e o conteúdo normativo da modernidade. Vila Velha: Quatro Irmãos. 